\title{
Is local anaesthesia hazardous to hearts?
}

\author{
The influence of two different dental local anaesthetic solutions on the haemodynamic responses of children undergoing \\ restorative dentistry: a randomised, single-blind, split-mouth study by J. G. Meechan, B. Cole and R. R. Welbury
}

Br Dent J 2001; 190: 502-504

\section{Objectives}

This investigation was designed to study the haemodynamic effects of two different local anaesthetic solutions during restorative dental treatment in children.

\section{Design \\ A randomised, single-blind, split-mouth cross-over design was employed using children undergoing bilaterally similar restorative treatments over two visits.}

\section{Setting}

The study was performed in a dental hospital paediatric dentistry department.

\section{Methods \\ Ten children participated. At one visit the local anaesthetic was $2 \%$ lidocaine (lignocaine) with 1:80,000 epinephrine (adrenaline); at the other the anaesthetic was $3 \%$ prilocaine with $0.03 \mathrm{IU} / \mathrm{ml}$ felypressin. Local anaesthetic was administered at a dose of $0.5 \mathrm{ml} / 10 \mathrm{~kg}$ body weight. Blood pressure and heart rate were measured before and during treatment with an automatic blood pressure recorder. Data were analysed by ANOVA and Student's paired $t$ test.}

\begin{abstract}
Results
Significant differences between treatments in diastolic blood pressure $(\mathrm{F}=2.37 ; P=0.05)$ and heart rate $(\mathrm{F}=2.98$;

$P<0.02)$ were noted. The heart rate increased ten minutes following the injection of the epinephrine-containing solution. The diastolic blood pressure fell 20 minutes after injection of lidocaine with epinephrine.
\end{abstract}

\section{Conclusion}

The choice of local anaesthetic solution influences the haemodynamic response during restorative treatment in children.
In Brief
- The choice of local anaesthetics in children affects the haemodynamic response to restorative dental treatment
- The use of an epinephrine (adrenaline) containing local anaesthetic increases heart rate and reduces diastolic blood pressure when compared with an epinephrine-free solution
- Lidocaine (lignocaine) with I:80,000 epinephrine and 3\% prilocaine with $0.031 \mathrm{U} / \mathrm{ml}$ felypressin were effective in obtaining anaesthesia for restorative dentistry in children when used at a dose of $0.5 \mathrm{ml}$ per $10 \mathrm{~kg}$ body weight

\section{Comment}

$\mathrm{T}$ his short article represents a further well designed study emanating from the University of Newcastle Dental School. It raises the issue of the effects of local anaesthetic drugs used for pain control on haemodynamic stability. The results presented here are clear and unambiguous. Under real conditions of restorative treatment in children the use of an epinephrine containing local anaesthetic solution caused an average increase in pulse rate of just over 5 beats per minute - approximately a $6 \%$ increase. The significance of this in clinical terms is difficult to assess. Even mild exercise will elevate pulse rates more than was shown here. Perhaps the data shows that the range of normal responses to the combination of local anaesthesia and dental treatment is within the range of normal haemodynamic responses

In addition the diastolic blood pressure dropped following the use of lidocaine by approximately $11 \%$. Again it raise the issue of the clinical significance of these changes. Although noticeably larger, perhaps the diastolic change is still within the range of normal responses to conservative treatment to local anaesthesia with lidocaine.

Is it of significance that these changes are occurring? Are they to serve as a gentle reminder that the use of local anaesthesia causes changes that at least have the potential for a significant and possibly hazardous effect on cardiovascular haemostasis? It is important to note that the authors were extremely careful in administering the local anaesthetic drugs according to a strictly controlled volume determined by the body weight of the child. It is possible that the more liberal use of local anaesthetic drugs commonly practised is more likely to cause the changes seen here and possibly to a greater degree.

The study is to some extent limited by the relatively small numbers, although we should not be too critical as to successfully recruit 10 children with suitable paired cavities needing treatment is a much greater task than is apparent at first sight. Any clinician who does not believe this should attempt this task for her/himself. Such a high quality experimental design is to be commended.

A feature of concern is the apparent separation of the measurements from the events of dental treatment. In terms of induction of haemodynamic changes it is likely to be the act of local anaesthesia (recorded here), use of fast drill, and use of slow drill that induce changes.

It is to be hoped that further work is conducted possibly with the use of continuous monitoring of heart rate and blood pressure to further define the haemodynamic changes and their relationship to the dental treatment procedures and local anaesthetic solutions used.

Is local anaesthesia hazardous to hearts? Almost certainly not, but it is important not to be complacent.

\section{Graham J Roberts}

Joint Professor of Paediatric Dentistry

The Eastman Dental Institute and The Institute of Child Health, University College, London 